with bracken to the gunwales and left two years exposed to frost and silting. It was to suffer much worse. By some lamentable failure of communications, the site was not scheduled as an ancient monument and, with Mrs Pretty dead, the land was taken over by the War Office as a battle training ground. It suffered accordingly.

When the British Museum team arrived this summer under the direction of Dr R. L. S. Bruce-Mitford of the Museum and Mr P. Ashbee, there was no trace of the ship. It was under five feet of silt with a machine gun emplacement dug through the stern and an unexploded bomb alongside which the Royal Engineers had to deal with.

Exactly why are the British Museum re-excavating the site? There are several reasons, all stemming from the fact that the original dig was such a hurried affair. Most importantly, complete details of the ship's construction were not recorded and these are of major importance. It is not every day that there is an opportunity of learning how a seventh century ship was built and this ship was no mere cenotaph-it was old and repaired and must have seen considerable service. The museum also wanted to look under the side of the ship for traces of the missing forty oars and steering paddle, to find the dimensions of the mound which had not been recorded and to sift through the mount of debris from the previous excavation looking for small fragments missing from the pieces of treasure.

The hunt has met with some success. Although all that was under the ship was two split logs supporting it, with no traces of the oars, the museum has found in the debris missing fragments from the treasure, notably the third of the boar's head decorations from the largest of the three hanging bowls and parts of the helmet and shield. These fragments are to be restored at the museum. A complete plaster cast of the hull has been made with great skill, and a fibre-glass positive will be taken from this. All that prevents the museum from making a full scale sailing replica of the ship is lack of money. It would cost $£ 20,000$.

There has always been a mystery about who, if anyone, was buried in this ship. Was it a grave or a cenotaph? Numismatists disagree over the dating of the thirty-seven gold coins in the ship's treasure, so it is not known who was reigning about the time of the burial and no skeleton was found in 1939 . $\mathrm{Mr} H$. Barker of the British Museum Laboratory is trying to determine if a body was ever in the burial by analysing the 2,000 iron rivets and samples of adjacent soil for deposits of iron phosphate.

In $1950 \mathrm{Mr}$ Barker reported (Nature, 166, 348; 1950) that the only fragment of material originally excavated in 1939 and then thought to be bone was, in fact, amorphous ferric phosphate. It did, however, contain carbon particles distributed as in calcined bone. Since the soil at Sutton Hoo is acid, the subsoil sand has a $p H$ of $4 \cdot 5$, and would decompose bone. Mr Barker suggests that phosphate liberated from bone reacts with any iron to produce ferric phosphate. This summer the position of the 2,000 or so rivets in the ship has been mapped and each will be analysed for deposits of ferric phosphate. Even though many of the rivets were displaced by the tanks that rolled over the ship in the $1940 \mathrm{~s}$, it is hoped that the pattern of distribution of any ferric phosphate may give a clue as to whether or not a body was buried with the ship.

\section{Crystal Chemistry of Proteins}

\section{from our Molecular Biology Correspondent}

THe pursuit of three dimensional protein structures by $\mathrm{X}$-ray analysis has given rise to a number of highly profitable by-products. Among these is the discovery, chiefly associated with F. M. Richards and his coworkers, that protein chemistry can be made to go on in the crystalline state and that X-ray diffraction can be applied dynamically to its observation. Richards and his associates have explored the diffusion of various reagents into ribonuclease and carboxypeptidase crystals, and have shown, for example, that substrates can be turned over in the erystal, unreacted substrate diffusing in and the reaction products out. By the introduction of a bifunctional reagent, intermolecular cross-links can be formed, so that an insoluble, but still enzymically active, crystal results.

The latest article (Wyckoff et al., J. Mol. Biol., $2 \%, 563$; 1967) describes elegant techniques for observing physical and chemical processes in protein crystals, gives a number of applications to the study of ribonuclease-S (pancreatic ribonuclease in which a peptide bond has been cleaved by exposure to subtilisin), and indicates how the methods have helped in the determination of the structure to $3 \AA$ resolution.

The method involves mounting the protein erystal (less than $1 \mathrm{~mm}$ in size) in a flow cell, which is placed in a diffractometer. Any suitable reflexion can then be selected for observation, and its intensity monitored as a function of time while an appropriate reagent is allowed to diffuse into the crystal. Rate curves are given for diffusion of ammonium sulphate and of inhibitors through the crystal. Dilution of the ammonium sulphate mother liquor leads to an intensity diminution in a half-time of 90 seconds. By contrast the diffusion of an inhibitor (an iodouridine phosphate) involves a half-time of 11 hours and the process is still measurably incomplete after three days. This enormous difference in the rates of penetration of small species is not explicable simply in terms of their diffu. sion coefficients, which differ only by a factor of about two: on the one hand the crystal lattice probably operates as a molecular sieve, impeding the progress of the larger nucleotide molecule; on the other, the binding of the inhibitor to the protein leads to a retardation (as in adsorption chromatography). A similar effect-titration of ionizing groups-is evidently responsible for the slowness of the response to a change in $p \mathrm{H}$ outside the crystal; in this case a change in the unit-cell dimensions is observed. The same system has been used to obtain binding curves for various inhibitors, to determine the number of sites-for the iodouridine phosphate, for example, a secondary binding site is surmised to exist-and to ascertain whether different ligands compete for the same site.

Since ligands can be washed out of a crystal with fresh ammonium sulphate solution, it has been possible to use a single crystal without disturbing its mounting in the goniometer for the comparison of a series of heavy-atom derivatives and the like. A single crystal was used in the same way for the collection of reflexions in the presence and absence of the isomorphous substituent, so that small intensity changes could be recognized with a high degree of confidence. The end-product of this work-the structure in detail of the enzyme-inhibitor complex-is promised soon. 